\title{
Layer-controlled growth of $\mathrm{MoS}_{2}$ on self-assembled flower-like $\mathrm{Bi}_{2} \mathrm{~S}_{3}$ for enhanced photocatalysis under visible light irradiation
}

\author{
Lu-Lu Long ${ }^{1}$, Jie-Jie Chen ${ }^{1}$, Xing Zhang ${ }^{1}$, Ai-Yong Zhang ${ }^{1,2}$, Yu-Xi Huang ${ }^{1}$, Qing Rong ${ }^{1}$ and Han-Qing Yu ${ }^{1}$ \\ Metal sulfide semiconductors, such as molybdenum disulfide $\left(\mathrm{MoS}_{2}\right)$ and bismuth trisulphide $\left(\mathrm{Bi}_{2} \mathrm{~S}_{3}\right)$, are of considerable \\ interest for their excellent applications in photocatalysis and in many other fields. However, the controllable synthesis of \\ $\mathrm{MoS}_{2} / \mathrm{Bi}_{2} \mathrm{~S}_{3}$ hybrid nanostructures remains a challenge. In this study, we report a unique sacrificial templating strategy for \\ preparing layer-controlled $\mathrm{MoS}_{2}$ on three-dimensional (3D) $\mathrm{Bi}_{2} \mathrm{~S}_{3}$ micro-flowers. For this approach, $\mathrm{Bi}_{2} \mathrm{~S}_{3}$ was utilized as a \\ sacrificial template to regulate the ion exchange, and the dosage of molybdenum was adjusted to tune the dynamic formation, \\ thus converting the $\mathrm{MoS}_{2}$ nanosheets on the $\mathrm{Bi}_{2} \mathrm{~S}_{3}$ micro-flowers from monolayer to multilayer. Such a 3D flower-like hybrid \\ nanostructure enables $\mathrm{MoS}_{2} / \mathrm{Bi}_{2} \mathrm{~S}_{3}$ to exhibit adsorption-promoted photocatalysis under visible light irradiation, especially for the \\ excellent photodegradation of low-concentration organic pollutants, for example, azo dye and atrazine. The observed superiority \\ of the 3D MoS${ }_{2} / \mathrm{Bi}_{2} \mathrm{~S}_{3}$ was mainly attributed to the increased mass transfer, robust light-harvesting capacity, improved charge \\ separation, lower oxygen-activation barrier and enhanced active oxygen yield. Our findings are of interest for the development of \\ novel S-based photocatalysts and provide a new opportunity to efficiently remove low-concentration refractory pollutants.
} NPG Asia Materials (2016) 8, e263; doi:10.1038/am.2016.46; published online 15 April 2016

\section{INTRODUCTION}

In recent years, metal sulfide semiconductors have been developed for environmental photocatalysis because of their narrow bandgaps, high sunlight absorption and satisfactory catalytic activity. ${ }^{1-4}$ Among them, $\mathrm{Bi}_{2} \mathrm{~S}_{3}$ is a promising visible light-driven photocatalyst owing to its low toxicity and narrow direct band gap of $\sim 1.3 \mathrm{eV} .{ }^{5}$ However, $\mathrm{Bi}_{2} \mathrm{~S}_{3}$ usually exhibits a substantially lower photocatalytic activity than expected, mainly because of severe charge recombination and structural photocorrosion. ${ }^{4}$ To achieve good carrier separation, the construction of a built-in electric field (band bending) is usually required. One effective way to enhance band bending is to create a thermodynamically driven heterojunction by incorporating another semiconductor, depending on the favored band offsets between the two semiconductors. ${ }^{6}$ Generally, the semiconductor that is incorporated as a cocatalyst to construct such a self-established heterojunction should possess good electric conductivity, a suitable energy structure and excellent electrochemical activity. ${ }^{7-11}$

As a typical layered metal sulfide, $\mathrm{MoS}_{2}$ has drawn increasing attention because of its layered structure similar to that of graphene, which is composed of three atom layers stacked together through Van der Waals interactions. ${ }^{12,13}$ Such a two-dimensional (2D) layeredcrystal structure provides convenient electron transfer and many active sites for interfacial adsorption. ${ }^{12,14}$ Moreover, the edge sites of $\mathrm{MoS}_{2}$ nanosheets are generally recognized as the thermodynamically active sites for electrochemical hydrogen evolution. ${ }^{15}$ As an important non-noble cocatalyst, $\mathrm{MoS}_{2}$ is a highly promising candidate for photocatalysis and many other applications. ${ }^{16-20}$ Thus, using $\mathrm{MoS}_{2}$ is reasonable for strengthening the visible light photocatalytic performance of $\mathrm{Bi}_{2} \mathrm{~S}_{3}$. ${ }^{21-24}$

As a cocatalyst, the morphology and nanostructure of $\mathrm{MoS}_{2}$, for example, nanoparticles, ${ }^{25}$ nanoclusters, ${ }^{26}$ nanospheres ${ }^{27}$ and nanosheets, ${ }^{19,28}$ have considerable effects on the catalytic performance of $\mathrm{MoS}_{2}$-activated hybrids. $\mathrm{MoS}_{2}$ in the form of nanosheets usually exhibits much better catalytic performance due to its 2D layered structure with a larger surface area and more active sites than those of other nanostructures. ${ }^{28}$ Furthermore, the layer of $\mathrm{MoS}_{2}$ also governs its properties and performance, as both the active sites and adsorption ability are substantially influenced by the layered nanostructure. ${ }^{28-30}$ Thus, constructing three-dimensional (3D) $\mathrm{MoS}_{2}$ heterostructures with suitable layers for catalytic applications is a reasonable approach. ${ }^{28,31,32}$ However, controlling the synthesis of $\mathrm{MoS}_{2}$ nanosheets as a cocatalyst remains a serious challenge, and most of the available $3 \mathrm{D}$ heterostructures are prepared by two or more steps. ${ }^{17,28,33,34}$ Hence, developing a simple, controllable general approach to synthesize $3 \mathrm{D} \quad \mathrm{MoS}_{2}$-based heterostructures is of considerable interest for cocatalyst applications.

${ }^{1}$ Department of Chemistry, CAS Key Laboratory of Urban Pollutant Conversion, University of Science and Technology of China, Hefei, China and ${ }^{2}$ Department of Municipal Engineering, Hefei University of Technology, Hefei, China

Correspondence: Dr A-Y Zhang or Professor H-Q Yu, Department of Chemistry, CAS Key Laboratory of Urban Pollutant Conversion, University of Science and Technology of China, Jinzhai Road 96, Hefei 230026, China.

E-mail: aiyzhang@ustc.edu.cn or hqyu@ustc.edu.cn

Received 25 October 2015; revised 23 January 2016; accepted 16 February 2016 
Herein, we report a simple general sacrificial template method to effectively regulate both the nanostructure of a $\mathrm{MoS}_{2}$ cocatalyst and the properties and catalytic performance of a novel $3 \mathrm{D} \mathrm{MoS}_{2} / \mathrm{Bi}_{2} \mathrm{~S}_{3}$ hybrid. The number of $\mathrm{MoS}_{2}$ layers could be simply and effectively regulated via this one-pot hydrothermal process based on an ionexchange mechanism. In this approach, $\mathrm{Bi}_{2} \mathrm{~S}_{3}$ was first generated and then acted as a sacrificial template for the subsequent $\mathrm{MoS}_{2}$ nanosheet growth from a monolayer to multiple layers. Moreover, a favorable 3D nanostructure could be effectively constructed when the number of $\mathrm{MoS}_{2}$ layers was regulated properly. To test an application, two typical organic pollutants, azo dye and atrazine, were degraded on this $3 \mathrm{D}$ $\mathrm{MoS}_{2} / \mathrm{Bi}_{2} \mathrm{~S}_{3}$ hybrid under visible light irradiation.

\section{MATERIALS AND METHODS}

\section{Reagents and materials}

All chemicals were reagent grade and used as received without further purification. $\mathrm{Bi}\left(\mathrm{NO}_{3}\right)_{3} \cdot 5 \mathrm{H}_{2} \mathrm{O}$, azo dye and atrazine were purchased from Aladdin Reagent (Shanghai, China). Sulfourea and sodium molybdate were purchased from Shanghai Reagent (Shanghai, China). The polycrystalline $\mathrm{TiO}_{2}$ P25 (Degussa, Frankfurt, Germany) had a mean particle size of $\sim 25 \mathrm{~nm}$, an anatase/rutile ratio of 80:20 and a specific surface area of $\sim 50 \mathrm{~m}^{2} \mathrm{~g}^{-1}$. Highpurity deionized water was used in this study.

\section{One-pot synthesis of $3 \mathrm{D} \mathrm{MoS} / \mathrm{Bi}_{2} \mathrm{~S}_{3}$}

First, $30 \mathrm{mg}$ of $\mathrm{Bi}\left(\mathrm{NO}_{3}\right)_{3} \cdot 5 \mathrm{H}_{2} \mathrm{O}$ was dissolved in deionized water, and then, a defined dosage of $\mathrm{Na}_{2} \mathrm{MoO}_{4}$ and an excess of sulfourea $(70 \mathrm{mg}$ ) were added to this solution. The total volume of the solution was fixed at $20 \mathrm{ml}$. The solution was transferred into a Teflon-lined stainless steel autoclave, which contained a suitably sized clean plate substrate, that is, carbon paper or glass, placed against the wall. The hydrothermal process was carried out at $200{ }^{\circ} \mathrm{C}$ for 24h. Then, the black flower-like $3 \mathrm{D} \mathrm{MoS}_{2} / \mathrm{Bi}_{2} \mathrm{~S}_{3}$ was collected from the plate substrate by sonication and centrifugation. Finally, the collected samples were washed repeatedly with deionized water and dried at $60^{\circ} \mathrm{C}$ for $12 \mathrm{~h}$. The samples prepared with $\mathrm{Na}_{2} \mathrm{MoO}_{4}$ dosages of $5,10,15,30$ and $60 \mathrm{mg}$ were designated as MoBi-5, MoBi-10, MoBi-15, MoBi-30 and MoBi-60, respectively.

For comparison, bare $\mathrm{Bi}_{2} \mathrm{~S}_{3}$ was prepared by the same procedure without the addition of $\mathrm{Na}_{2} \mathrm{MoO}_{4}$, whereas bare $\mathrm{MoS}_{2}$ was prepared by the same procedure without the addition of $\mathrm{Bi}\left(\mathrm{NO}_{3}\right)_{3} \cdot 5 \mathrm{H}_{2} \mathrm{O}$.

\section{Characterization}

The morphology and structure of the samples were characterized using a fieldemission scanning electron microscope (SIRION200; FEI, Eindhoven, The Netherlands). Transmission electron imaging selected-area electron diffraction was performed on a high-resolution transmission electron microscope (TEMJEM-ARM200F; JEOL, Tokyo, Japan). The chemical compositions of the samples were characterized by an energy dispersive X-ray analyzer (GENESIS; EDAX, Mahwah, NJ, USA) fitted to the TEM chamber. X-ray diffraction (XRD) was carried out using an X'celerator detector (X'pert PANalytical BV, Almelo, The Netherlands). X-ray photoelectron spectroscopy was performed using an ESCALAB250 (Thermo Fisher, San Jose, CA, USA). The diffuse reflectance spectra were measured using a UV/Vis spectrophotometer (UV 2550; Shimadzu, Tokyo, Japan). The surface area was measured by the BrunauerEmmett-Teller method with a Builder 4200 instrument (Tristar II 3020M; Micromeritics, Norcross, GA, USA) in liquid nitrogen. The working electrode was prepared by using dip-coating technology (photocatalyst: $1.0 \mathrm{gl}^{-1}$ ). Electrochemical impedance spectroscopy was measured by applying an AC voltage with an amplitude of $-0.33 \mathrm{~V}$ (versus $\mathrm{Ag} / \mathrm{AgCl}$ ) within a frequency range from $10^{5}$ to $10^{-1} \mathrm{~Hz}$ in a $0.2 \mathrm{M} \mathrm{Na} \mathrm{Na}_{2} \mathrm{~S} \cdot 9 \mathrm{H}_{2} \mathrm{O}$ aqueous solution. The photocurrent was measured at $0.25 \mathrm{~V}$ (versus $\mathrm{Ag} / \mathrm{AgCl}$ ) in $0.1 \mathrm{M} \mathrm{Na} \mathrm{Na}_{4}$ aqueous solution. The oxygen reduction reaction tests were conducted in $0.1 \mathrm{~m} \mathrm{KOH}$ solution with a rotating-disk electrode (Pine Research Instrumentation, Grove, PA, USA). Mott-Schottky plots were obtained using impedance measurements at a fixed frequency of $1000 \mathrm{~Hz}$ in an applied voltage range of -0.50 to $1.0 \mathrm{~V}$ in $0.1 \mathrm{M} \mathrm{Na}_{2} \mathrm{SO}_{4}$ aqueous solution $(\mathrm{pH}=\sim 7.0)$. All electrochemical tests were conducted in a three-electrode electrochemical system using a CHI660 potentiostat (Chenhua, Shanghai, China), and a saturated $\mathrm{Ag} / \mathrm{AgCl}$ $(3.0 \mathrm{M} \mathrm{KCl})$ was used as the reference electrode, with a standard potential of $0.197 \mathrm{~V}$ versus a normal hydrogen electrode (NHE). The fluorescence tests were conducted in a custom-built photoreactor with an effective volume of $60 \mathrm{ml}$. The light source was a $500 \mathrm{~W}$ Xe arc lamp (PLS-SXE500; Trusttech, Beijing, China), with a $10 \mathrm{~cm}$ infrared water filter and a Pyrex filter $(\lambda>420 \mathrm{~nm})$. For each test, $50 \mathrm{ml}$ of aqueous solution containing $0.1 \mathrm{~g} \mathrm{l}^{-1}$ catalyst, $1 \mathrm{~mm}$ terephthalic acid and $0.01 \mathrm{M} \mathrm{NaOH}$ were used. Fluorescence spectra were recorded using a spectrofluorophotometer (RF-5301PC; Shimadzu). The ESR signal spin-trapped by 5,5-dimethyl-pyrroline-N-oxide was recorded on a Bruker spectrometer (A300, Bruker, Karlsruhe, Germany) with the following settings: center field $=3512 \mathrm{G}$, microwave frequency $=9.86 \mathrm{GHz}$ and power $=6.36 \mathrm{~mW}$. The water contact angle was measured with a contact angle analyzer (JC2000A; Powereach, Beijing, China). The zeta potential analysis was performed on a Zetasizer (Nano-Z; Malvern, Worcester, UK), in a folded capillary cell (DTS1060) made from polycarbonate with gold-plated beryllium/copper electrodes.

\section{Photocatalytic degradation tests}

The photocatalytic activity of $3 \mathrm{D} \mathrm{MoS} / \mathrm{Bi}_{2} \mathrm{~S}_{3}$ was evaluated by the degradation of rhodamine $\mathrm{B}(\mathrm{RhB})$ and atrazine under visible light irradiation, with $0.15 \mathrm{M}$ $\mathrm{Na}_{2} \mathrm{SO}_{3}$ and $0.1 \mathrm{M} \mathrm{Na} \mathrm{N}_{2} \mathrm{~S}$ as sacrificial reagents. A $500 \mathrm{~W}$ xenon arc lamp equipped with a pass filter $(\lambda>420 \mathrm{~nm})$ was used as a simulated light source. For the RhB degradation, $4 \mathrm{mg}$ of $\mathrm{MoS}_{2} / \mathrm{Bi}_{2} \mathrm{~S}_{3}$ was dispersed into $20 \mathrm{ml} \mathrm{RhB}$ aqueous solution $\left(5 \mathrm{mg} \mathrm{l}^{-1}\right)$, whereas for the atrazine degradation, $30 \mathrm{mg}$ of the photocatalyst was dosed into $60 \mathrm{ml}$ atrazine solution $\left(5 \mathrm{mgl}^{-1}\right)$. Before irradiation, the solution was sonicated for $10 \mathrm{~min}$ and then stirred for $20 \mathrm{~min}$. During the reaction, $1-\mathrm{ml}$ aliquots were sampled regularly. The amounts of $\mathrm{RhB}$ and atrazine in the aliquots were analyzed using a UV-visible spectrophotometer (UV-2401PC, Shimadzu) and high-performance liquid chromatography (1100; Agilent, Palo Alto, CA, USA), respectively, with a variable-wavelength detector set at $220 \mathrm{~nm}$. The mobile phase consisted of $\mathrm{H}_{2} \mathrm{O}$ and methanol (50:50), and the flow rate was $0.8 \mathrm{ml} \mathrm{min}^{-1}$. The total organic carbon was measured by a total organic carbon analyzer (Multi N/C 2100; Analytik Jena, Jena, Germany).

\section{RESULTS AND DISCUSSION}

\section{Morphology and structure of $3 \mathrm{D} \mathrm{MoS}_{2} / \mathrm{Bi}_{2} \mathrm{~S}_{3}$}

The prepared $\mathrm{Bi}_{2} \mathrm{~S}_{3}$ with the micro-flower morphology was self-assembled from micro-rods with a length of $2-3 \mu \mathrm{m}$ and a width of $200-400 \mathrm{~nm}$ (Supplementary Figure S1a). Figures 1a-c shows typical SEM images of $3 \mathrm{D} \mathrm{MoS}_{2} / \mathrm{Bi}_{2} \mathrm{~S}_{3}(\mathrm{MoBi}-30)$ at low and high magnifications, in which most of the $\mathrm{Bi}_{2} \mathrm{~S}_{3}$ micro-flowers were uniformly covered by $\mathrm{MoS}_{2}$ nanosheets. A large number of $\mathrm{MoS}_{2}$ nanosheets were directly grown on each micro-rod of the $\mathrm{Bi}_{2} \mathrm{~S}_{3}$ micro-flowers, forming the 3D flower-like heterostructure (Figure 1d). The shell thickness and the core diameter were identified to be $\sim 50$ and $\sim 100 \mathrm{~nm}$, respectively. During the hydrothermal growth, $\mathrm{Bi}_{2} \mathrm{~S}_{3}$ could act as the sacrificial template to provide active sites for $\mathrm{MoS}_{2}$ growth. In the absence of the $\mathrm{Bi}_{2} \mathrm{~S}_{3}$ template, the $\mathrm{MoS}_{2}$ nanosheets similarly self-assembled to form flower-like microspheres (Supplementary Figures S1b-f).

The crystal structure of the $3 \mathrm{D} \mathrm{MoS}_{2} / \mathrm{Bi}_{2} \mathrm{~S}_{3}$ heterostructures was further investigated by XRD (Supplementary Figure S2a). The diffraction peaks of the $\mathrm{MoS}_{2}$ nanosheets corresponded well to the standard peaks of the $\mathrm{MoS}_{2}$ hexagonal phase (JCPDS card No. 371492; Supplementary Figure S2b), and the diffraction peaks of $\mathrm{Bi}_{2} \mathrm{~S}_{3}$ could be indexed to the crystalline planes of the $\mathrm{Bi}_{2} \mathrm{~S}_{3}$ orthorhombic phase (JCPDS card No. 17-0320; Supplementary Figure S2c). Moreover, all the diffraction peaks of these two semiconductors were simultaneously observed in the XRD pattern of $3 \mathrm{D} \mathrm{MoS}_{2} / \mathrm{Bi}_{2} \mathrm{~S}_{3}$.

In addition, 3D $\mathrm{MoS}_{2} / \mathrm{Bi}_{2} \mathrm{~S}_{3}$ (MoBi-30) was further observed by high-resolution TEM. The $\mathrm{MoS}_{2}$ nanoflakes and the $\mathrm{Bi}_{2} \mathrm{~S}_{3}$ micro-rods 

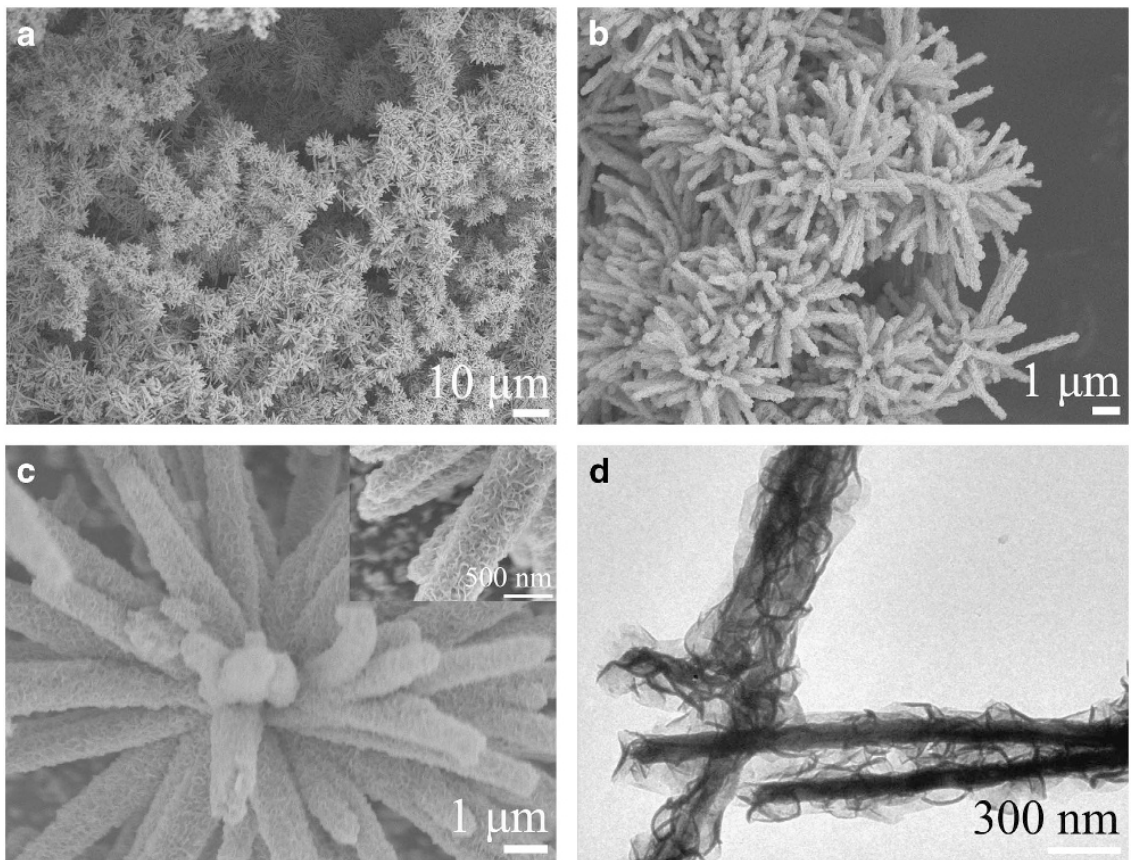

Figure 1 Scanning electron microscope (SEM) (a-c) and transmission electron microscope (TEM) (d) images of 3D $\mathrm{MoS}_{2} / \mathrm{Bi}_{2} \mathrm{~S}_{3}\left(\mathrm{MoBi}^{-30}\right)$.

were densely interconnected (Figure 2a). The selected-area electron diffraction patterns (Figure 2a, inset) indicated two-component crystalline characteristics: one set of spots was indexed to single crystalline $\mathrm{Bi}_{2} \mathrm{~S}_{3}$ micro-rods, and another set of rings was attributed to the $\mathrm{MoS}_{2}$ nanosheets, arising from the stacking of $\mathrm{MoS}_{2}$ nanosheets with different crystallographic orientations. Furthermore, the high-resolution TEM images of the $\mathrm{Bi}_{2} \mathrm{~S}_{3}$ micro-rods (Figure 2b), $\mathrm{MoS}_{2}$ nanosheets (Figure 2c) together with the selected-area electron diffraction patterns further confirm the crystal structure of the $3 \mathrm{D}$ $\mathrm{MoS}_{2} / \mathrm{Bi}_{2} \mathrm{~S}_{3}$. The inter-plane spacings of 0.80 and $0.39 \mathrm{~nm}$ could be assigned to the (110) and (001) planes of the orthorhombic $\mathrm{Bi}_{2} \mathrm{~S}_{3}$, respectively. The fringes with lattice spacings of 0.27 and $0.57 \mathrm{~nm}$ corresponded to the (100) and (002) planes of $\mathrm{MoS}_{2}$, respectively. The characteristic peak of the (002) crystalline plane at $14.2^{\circ}$ in the XRD pattern suggests the ordered stacking of S-Mo-S layers (Figure 2d). At least ten layers of $\mathrm{MoS}_{2}$ nanosheets grew on the $\mathrm{Bi}_{2} \mathrm{~S}_{3}$ micro-rods. The high-resolution TEM observations indicate that $\mathrm{Bi}_{2} \mathrm{~S}_{3}$ nanorods grew along the [001] crystallographic direction with the (110) surface as the outside surface, in contact with the (001) surface of $\mathrm{MoS}_{2}$.

The crystal surface matching of the $\mathrm{Bi}_{2} \mathrm{~S}_{3}$ and $\mathrm{MoS}_{2}$ could be explained at the atomic level by the structural model of the $\mathrm{MoS}_{2} / \mathrm{Bi}_{2} \mathrm{~S}_{3}$. The $\mathrm{Bi}_{2} \mathrm{~S}_{3}$ nanorod could be constructed from the $\mathrm{Bi}_{2} \mathrm{~S}_{3}$ crystal based on the (110) plane. The XRD results show that the crystal structures of $\mathrm{Bi}_{2} \mathrm{~S}_{3}$ and $\mathrm{MoS}_{2}$ in this heterostructure each belonged to orthorhombic and hexagonal crystal systems, respectively, corresponding to the space groups of $\mathrm{Pbnm}$ and $\mathrm{P} 63 / \mathrm{mmc}$, respectively. The crystal cells of orthorhombic $\mathrm{Bi}_{2} \mathrm{~S}_{3}$ and hexagonal $\mathrm{MoS}_{2}$ are shown in Supplementary Figures S3a and b. Then, the (110) surface of the $\mathrm{Bi}_{2} \mathrm{~S}_{3}$ and the (001) surface of $\mathrm{MoS}_{2}$ were cleaved from the crystal structures. The distance between adjacent $\mathrm{Bi}$ atoms exposed on the (110) crystal surface of orthorhombic $\mathrm{Bi}_{2} \mathrm{~S}_{3}$ was $15.864 \AA$, and $\mathrm{S}$ atoms appeared at $3.168 \AA$ intervals along the (001) surface of hexagonal $\mathrm{MoS}_{2}$ (Figure 2e). Thus, five intervals $(15.840 \AA)$ of the $S-S$ distance on the (001) surface of the $\mathrm{MoS}_{2}$ nanosheet matched well with the $\mathrm{Bi}-\mathrm{Bi}$ distance on the outside surface of the $\mathrm{Bi}_{2} \mathrm{~S}_{3}$ nanorod (Figure 2e). This might be beneficial for the growth of the $\mathrm{MoS}_{2}$ nanosheet on the $\mathrm{Bi}_{2} \mathrm{~S}_{3}$ nanorod via the interaction of $\mathrm{S}$ and $\mathrm{Bi}$ atoms to form the heterostructure. The high-resolution TEM image and energy dispersive X-ray mappings (Figures $2 \mathrm{f}-\mathrm{i}$ ) provide more evidence for the combination of $\mathrm{MoS}_{2}$ nanosheets and $\mathrm{Bi}_{2} \mathrm{~S}_{3}$ micro-rods. $\mathrm{A} \mathrm{Bi}_{2} \mathrm{~S}_{3}$ micro-rod was located in the center of the $3 \mathrm{D}$ heterostructure, whereas $\mathrm{MoS}_{2}$ nanosheets were homogeneously distributed over the whole micro-rod. A uniform distribution of $\mathrm{Bi}, \mathrm{Mo}$ and $\mathrm{S}$ throughout the $3 \mathrm{D}$ $\mathrm{MoS}_{2} / \mathrm{Bi}_{2} \mathrm{~S}_{3}$ was clearly observed (Figures $2 \mathrm{f}-\mathrm{i}$ ), with an atomic ratio of 11.63:29.49:58.89 (Supplementary Figure S4). The surface composition and chemical states of the heterostructures were characterized, and the results confirmed the successful growth of $\mathrm{MoS}_{2}$ and $\mathrm{Bi}_{2} \mathrm{~S}_{3}$ (Supplementary Figure S5), which agrees well with the XRD results (Supplementary Figure S2). Moreover, both Mo 3D high-resolution $\mathrm{X}$-ray photoelectron spectroscopy spectra could be fitted to the two components associated with the $1 \mathrm{~T}$ and $2 \mathrm{H}$ phases, ${ }^{15,18,21}$ indicating the co-existence of these two polymorphs (Supplementary Figures S5c,i). In addition, much lower surface areas were obtained for both bare $\mathrm{Bi}_{2} \mathrm{~S}_{3}$ and $\mathrm{MoS}_{2}$, that is, 1.67 and $5.94 \mathrm{~m}^{2} \mathrm{~g}^{-1}$, respectively. This was attributed mainly to either the low-dimensional morphology or the much larger apparent thickness of the nanosheets and their severe aggregation (Supplementary Figures S1b-f) ${ }^{25,35}$ compared with 3D $\mathrm{MoS}_{2} / \mathrm{Bi}_{2} \mathrm{~S}_{3}\left(25.65 \mathrm{~m}^{2} \mathrm{~g}^{-1}\right.$, Supplementary Figure S6).

Formation mechanism of $3 \mathrm{D} \mathrm{MoS}_{2} / \mathrm{Bi}_{2} \mathrm{~S}_{3}$

As the SEM images of the transitional structures with increasing reaction times provide more direct evidence (Supplementary Figure S7), the cation-exchange formation mechanism of the 3D $\mathrm{MoS}_{2} / \mathrm{Bi}_{2} \mathrm{~S}_{3}$ micro-flowers is proposed (Figure 3). In the first step, randomly packed amorphous $\mathrm{Bi}_{2} \mathrm{~S}_{3}$ nanowires were initially generated as a precursor, while $\mathrm{MoO}_{4}{ }^{2-}$ and sulfur released by sulfourea were distributed around the $\mathrm{Bi}_{2} \mathrm{~S}_{3}$ nanowires, and a small amount of $\mathrm{MoS}_{2}$ nanosheet subunits appeared as a scaffold on the surface of the $\mathrm{Bi}_{2} \mathrm{~S}_{3}$ nanowires (Supplementary Figures $\mathrm{S} 7 \mathrm{a}-\mathrm{d}, 4-12 \mathrm{~h}$ ); $\mathrm{Bi}_{2} \mathrm{~S}_{3}$ nanowires further grew into micro-rods, and the $\mathrm{MoS}_{2}$ nanosheets became much 

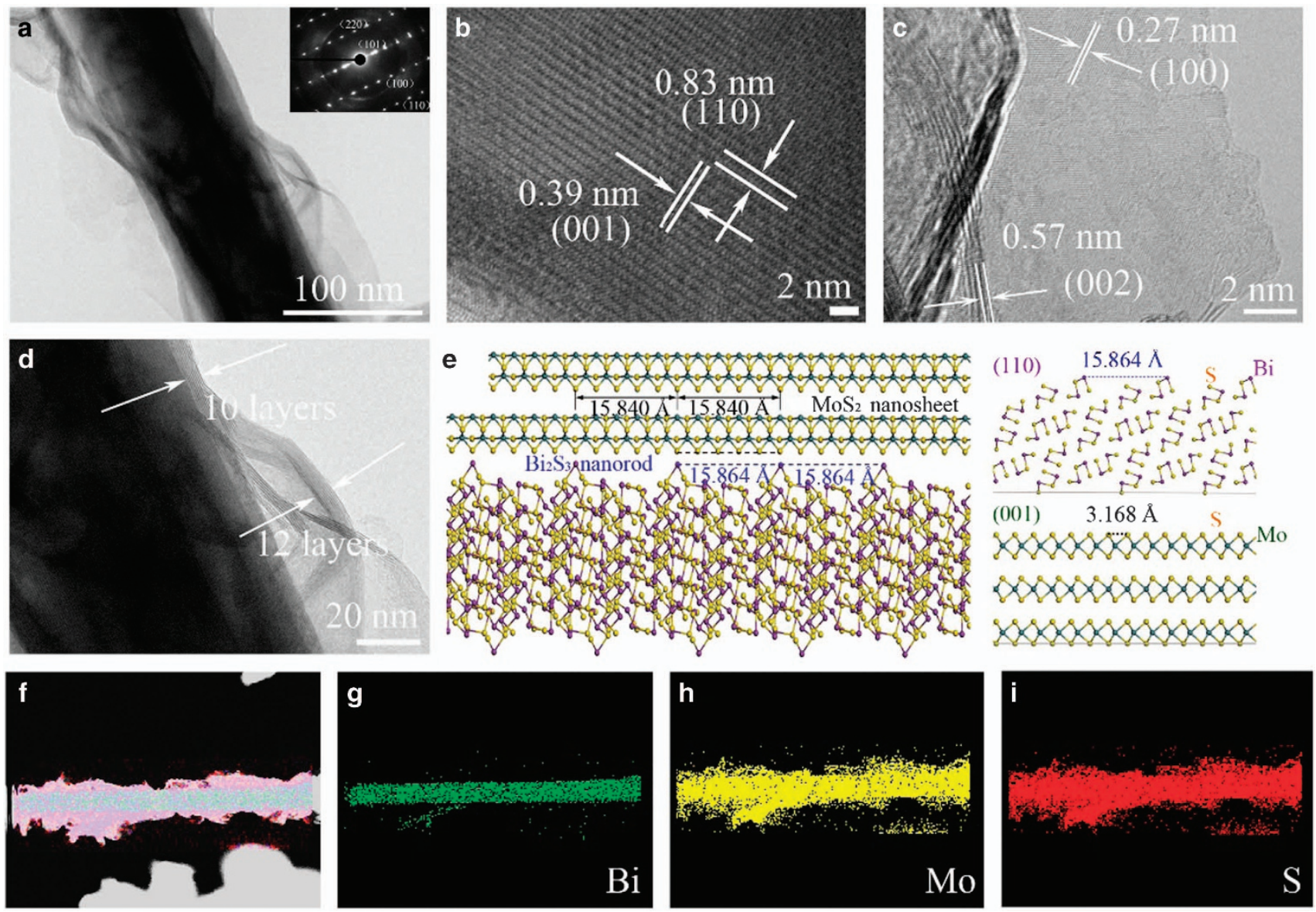

Figure 2 Transmission electron microscope (TEM) (a, d) and high-resolution transmission electron microscope (HRTEM) (b, c) images of 3D $\mathrm{MoS}_{2} / \mathrm{Bi}_{2} \mathrm{~S}_{3}$ (MoBi-30), the inset of $\mathbf{a}$ is its selected-area electron diffraction (SAED) pattern, and the thickness of one $\mathrm{MoS}_{2}$ layer is $\sim 0.6 \mathrm{~nm}$; crystal surface match between the (001) surface of the $\mathrm{MoS}_{2}$ nanosheet and the outside surface of the $\mathrm{Bi}_{2} \mathrm{~S}_{3}$ nanorod, the (110) surface of orthorhombic $\mathrm{Bi}_{2} \mathrm{~S}_{3}$ with the distance $\left(15.864 \AA\right.$ ) between adjacent $\mathrm{Bi}$ atoms and the (001) surface cleaved from hexagonal $\mathrm{MoS}_{2}$, the $\mathrm{S}$ atom appears at the intervals of $3.168 \AA$ (e); STEM image and the energy dispersive X-ray (EDX) elemental mappings of $\mathrm{Bi}$, Mo and $\mathrm{S}(\mathbf{f}-\mathbf{i})$.

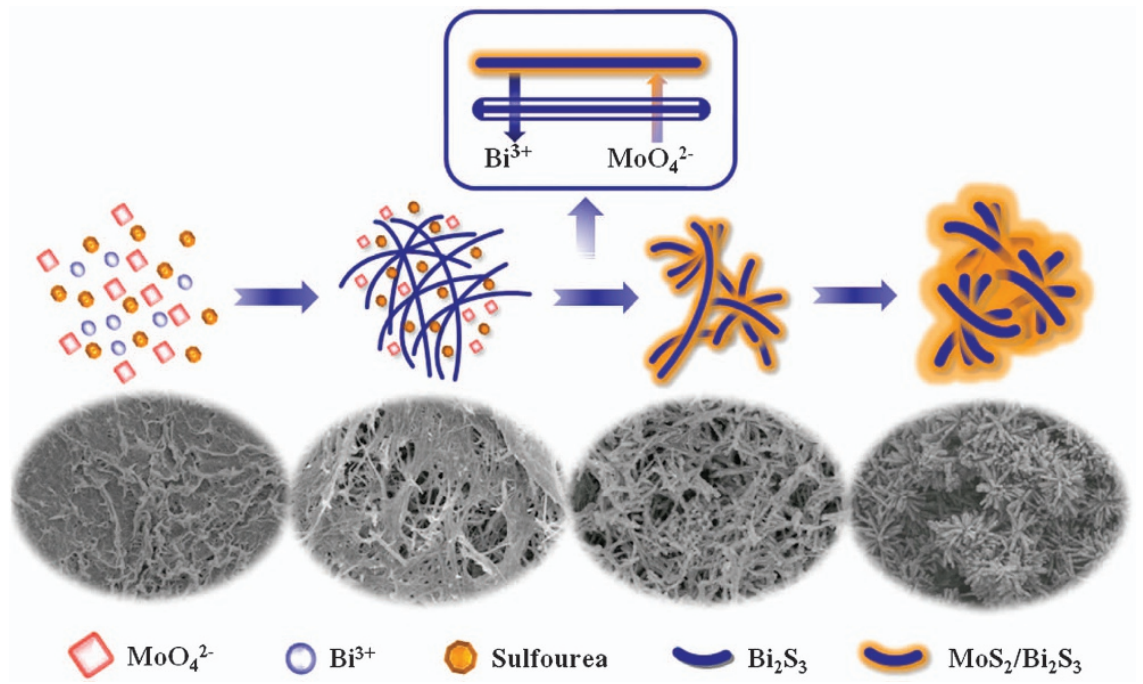

Figure 3 Formation of $3 \mathrm{D} \mathrm{MoS} / \mathrm{Bi}_{2} \mathrm{~S}_{3}$ via a cation-exchange mechanism. 

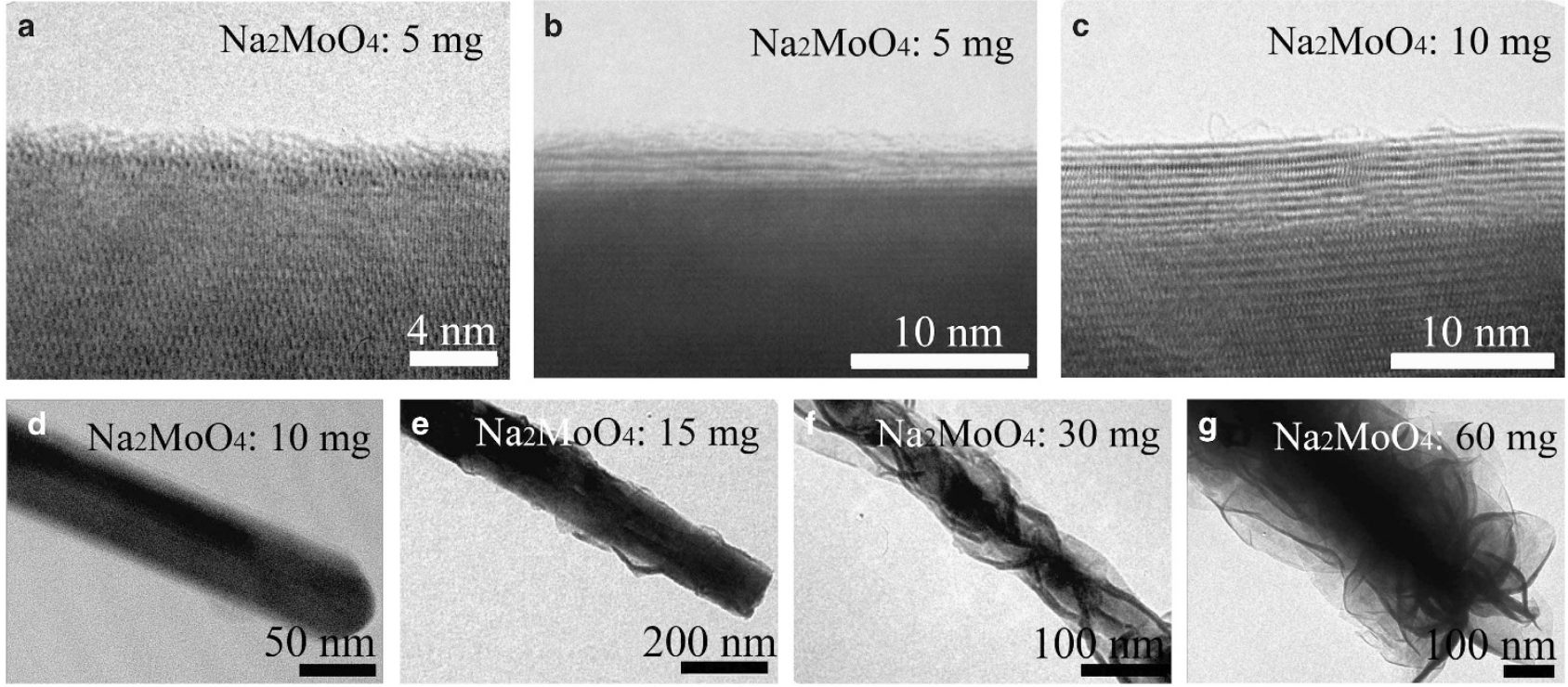

Figure 4 High-resolution transmission electron microscope (HRTEM) and transmission electron microscope (TEM) images of $3 \mathrm{D} \mathrm{MoS}_{2} / \mathrm{Bi}_{2} \mathrm{~S}_{3}$ hybrid with different layers of $\mathrm{MoS}_{2}$ nanosheets: MoBi-5 (a, b), MoBi-10 (c, d), MoBi-15 (e), MoBi-30 (f) and MoBi-60 (g).

thicker as the reaction progressed (Supplementary Figure S7e, 16h). Then, $\mathrm{Bi}_{2} \mathrm{~S}_{3}$ nanowires continuously became increasingly thicker and started to overlap each other, ultimately self-assembling into $3 \mathrm{D}$ $\mathrm{MoS}_{2} / \mathrm{Bi}_{2} \mathrm{~S}_{3}$ micro-flowers, which were comprised of $\mathrm{Bi}_{2} \mathrm{~S}_{3}$ micro-rods uniformly coated by the layer-controlled $\mathrm{MoS}_{2}$ nanosheets (Supplementary Figure S7f, 24h). With the increasing hydrothermal time, the thickness of the $\mathrm{MoS}_{2}$ layer progressively increased, and the $\mathrm{Bi}_{2} \mathrm{~S}_{3}$ nanorods became increasingly thinner (Supplementary Figure $\mathrm{S7g}, 27 \mathrm{~h}$ ). When the hydrothermal time was prolonged to $30 \mathrm{~h}, \mathrm{Bi}_{2} \mathrm{~S}_{3}$ nanorods almost completely disappeared, and the thickness of $\mathrm{MoS}_{2}$ layer peaked (Supplementary Figures S7h,i). These SEM images provide solid evidence that the as-formed $\mathrm{Bi}_{2} \mathrm{~S}_{3}$ acted as a sacrificial template for the subsequent $\mathrm{MoS}_{2}$ growth and the final formation of the $3 \mathrm{D} \mathrm{MoS}_{2} / \mathrm{Bi}_{2} \mathrm{~S}_{3}$ hybrid.

The XRD results further validate the SEM observations (Supplementary Figure S8). The XRD pattern of the sample isolated at $6 \mathrm{~h}$ clearly shows weak diffraction peaks, which are coincident with the orthorhombic phase of $\mathrm{Bi}_{2} \mathrm{~S}_{3}$ (JCPDS 17-0320). This indicates its primary formation as a sacrificial precursor at the initial stage of the hydrothermal process. In comparison, no diffraction peaks assigned to $\mathrm{MoS}_{2}$ were detected, which might be mainly due to its small dosage and/or high dispersity. After the reaction time was increased to $12 \mathrm{~h}$, the intensity of the $\mathrm{Bi}_{2} \mathrm{~S}_{3}$ diffraction peaks substantially increased, and the characteristic XRD peak for the hexagonal phase of $\mathrm{MoS}_{2}$ positioned at $\sim 14.0^{\circ}$ could be clearly detected (JCPDS 37-1492), indicating the continuous growth of both $\mathrm{Bi}_{2} \mathrm{~S}_{3}$ and $\mathrm{MoS}_{2}$. The intensity of the diffraction peaks of $\mathrm{Bi}_{2} \mathrm{~S}_{3}$ peaked at $16 \mathrm{~h}$ then progressively decreased with the continuous increase in the $\mathrm{MoS}_{2}$ dosage. When the hydrothermal process was further prolonged to $30 \mathrm{~h}$, the intensity of the $\mathrm{MoS}_{2}$ diffraction peaks reached a maximum, whereas the diffraction peaks for the orthorhombic phase of $\mathrm{Bi}_{2} \mathrm{~S}_{3}$ became considerably weaker, as in the first $6 \mathrm{~h}$ of the reaction, which should mainly be attributed to the substantial increase in the dosage of $\mathrm{MoS}_{2}$ nanosheets locally grown on the surface of $\mathrm{Bi}_{2} \mathrm{~S}_{3}$ nanorods. These time-dependent phase structures shown by the XRD results agree well with the time-dependent morphologies from the SEM images (Supplementary Figure S7).
Furthermore, the TEM images that were isolated from the reaction mixture at $16-30 \mathrm{~h}$ also provide direct proof for the cation-exchange formation mechanism of the $3 \mathrm{D} \mathrm{MoS}_{2} / \mathrm{Bi}_{2} \mathrm{~S}_{3}$ hybrid (Supplementary Figure S9). When the hydrothermal time was prolonged from 16 to $30 \mathrm{~h}$, the thickness of $\mathrm{MoS}_{2}$ layer progressively increased, and the $\mathrm{Bi}_{2} \mathrm{~S}_{3}$ nanowires continuously became increasingly thinner (Supplementary Figures S9a-c, 16-27h). When the hydrothermal time was further prolonged to $30 \mathrm{~h}, \mathrm{Bi}_{2} \mathrm{~S}_{3}$ almost completely disappeared, and the thickness of the $\mathrm{MoS}_{2}$ layer reached its maximum value (Supplementary Figure S9d). The TEM images of the transitional structures isolated at different reaction times further prove that the $3 \mathrm{D}$ $\mathrm{MoS}_{2} / \mathrm{Bi}_{2} \mathrm{~S}_{3}$ hybrid formed using $\mathrm{Bi}_{2} \mathrm{~S}_{3}$ nanorods as a sacrificial template for localized $\mathrm{MoS}_{2}$ growth via the cation-exchange mechanism. After $30 \mathrm{~h}$ of hydrothermal reaction, most of the $\mathrm{Bi}_{2} \mathrm{~S}_{3}$ nanowires were converted into $\mathrm{MoS}_{2}$ under the driving force of the solubility difference in aqueous solution.

Although the solubility of $\mathrm{Bi}_{2} \mathrm{~S}_{3}$ in aqueous solution is much lower than $\mathrm{MoS}_{2}$ with $K_{\text {sp }}$ values of $1.0 \times 10^{-97}$ and $2.2 \times 10^{-56}$, respectively, ${ }^{36} \mathrm{MoS}_{2}$ nanosheets were formed by utilizing $\mathrm{Bi}_{2} \mathrm{~S}_{3}$ nanorods as a sacrificial precursor, as illustrated by the SEM, TEM and XRD results (Figures 1,2 and 4 and Supplementary Figures S7). The $\mathrm{MoS}_{2}$ nanosheets grew with the sulfur from the as-formed $\mathrm{Bi}_{2} \mathrm{~S}_{3}$ nanorods, rather than with an auxiliary source from the reaction solution, that is, thiourea. The main reason for such an unexpected structural transition from the low-solubility $\mathrm{Bi}_{2} \mathrm{~S}_{3}$ to the high-solubility $\mathrm{MoS}_{2}$ might mainly be attributed to the strong complexing between the added thiourea, a typical organic complexing agent, and the lattice bismuth species in the $\mathrm{Bi}_{2} \mathrm{~S}_{3}$ nanorods, as in the spectrophotometric determination of bismuth $\left(\mathrm{Bi}^{3+}+\mathrm{CS}\left(\mathrm{NH}_{2}\right)_{2} \rightarrow\left(\mathrm{BiCS}\left(\mathrm{NH}_{2}\right)_{2}\right)^{3+}\right.$, number of ligands $\left.=6, \lg \beta_{n}=11.9\right) \cdot{ }^{37,38}$ From the standpoint of crystal growth, the presence of thiourea sufficiently facilitated the lattice $\equiv \mathrm{Bi}$ (III) release from the crystal structure of the $\mathrm{Bi}_{2} \mathrm{~S}_{3}$ nanorods, which served as a unique substrate, rather than as a typical catalyst for the subsequent $\mathrm{MoS}_{2}$ formation. This favored the strong thiourea complexation of $\mathrm{Bi}^{3+}$ on the surface of the $\mathrm{Bi}_{2} \mathrm{~S}_{3}$ nanorods, and could be anticipated to shift the reaction equilibrium toward $\mathrm{MoS}_{2}$ formation by recombining the liberated sulfur species from the $\mathrm{Bi}_{2} \mathrm{~S}_{3}$ nanorods with the molybdenum species from the aqueous solution, $\mathrm{MoO}_{4}{ }^{2-}$ 
and therefore to change the thermodynamic balance between the $K_{\mathrm{sp}}$ of $\mathrm{Bi}_{2} \mathrm{~S}_{3}$ and $\mathrm{MoS}_{2}$, as mentioned above. Similar results have been previously reported. ${ }^{39,40}$ Moreover, in addition to $\mathrm{Bi}_{2} \mathrm{~S}_{3}$, another composite, that is, $\mathrm{Sb}_{2} \mathrm{~S}_{3}$, could also act as a template for the controllable growth of $\mathrm{MoS}_{2}$ nanosheets (Supplementary Figure S10). As a result, the developed method using a sacrificial template might be used as a general way to synthesize $\mathrm{MoS}_{2}$ nanosheet-based hybrid.

The layers of $\mathrm{MoS}_{2}$ nanosheets on the $\mathrm{Bi}_{2} \mathrm{~S}_{3}$ micro-rods and in the 3D $\mathrm{MoS}_{2} / \mathrm{Bi}_{2} \mathrm{~S}_{3}$ heterostructure could be effectively regulated by controlling the dosage of $\mathrm{Na}_{2} \mathrm{MoO}_{4}$ added to the hydrothermal reaction (Figure 4). When a small amount (that is, $5 \mathrm{mg}$ ) of $\mathrm{Na}_{2} \mathrm{MoO}_{4}$ was added, amorphous $\mathrm{MoS}_{2}$ or monolayer $\mathrm{MoS}_{2}$ grew on the surface of the $\mathrm{Bi}_{2} \mathrm{~S}_{3}$ nanorods (Figures $4 \mathrm{a}$ and $\mathrm{b}$ ). By increasing the dosage of $\mathrm{Na}_{2} \mathrm{MoO}_{4}$ to $15 \mathrm{mg}$, the number of $\mathrm{MoS}_{2}$ layers on the $\mathrm{Bi}_{2} \mathrm{~S}_{3}$ nanorods could be substantially increased (Figures $4 \mathrm{c}-\mathrm{e}$ and Supplementary Figure S11a). At an adequate dosage of $\mathrm{Na}_{2} \mathrm{MoO}_{4}$, that is, $30 \mathrm{mg}$, the $\mathrm{MoS}_{2}$ film could be sufficiently thick, and the morphology of $3 \mathrm{D} \mathrm{MoS}_{2} / \mathrm{Bi}_{2} \mathrm{~S}_{3}$ was well-defined (Figure $4 \mathrm{f}$ ). An excessive dose of $\mathrm{Na}_{2} \mathrm{MoO}_{4}$, that is, $60 \mathrm{mg}$, resulted in the much thicker and more densely grown $\mathrm{MoS}_{2}$ nanosheets with decreased inter-spaces (Figure $4 \mathrm{~g}$ and Supplementary Figure S11b). These results clearly indicate that the dosage of added $\mathrm{Na}_{2} \mathrm{MoO}_{4}$ had a dominant role in controlling the layers of $\mathrm{MoS}_{2}$ nanosheets locally grown on the $\mathrm{Bi}_{2} \mathrm{~S}_{3}$ surface.

Adsorption-promoted degradation of low-concentration refractory pollutants by $3 \mathrm{D} \mathrm{MoS}_{2} / \mathrm{Bi}_{2} \mathrm{~S}_{3}$

For the photocatalytic degradation of refractory pollutants, the overall rate resistance should be the summation of the mass-transfer resistance and the chemical reaction resistance. Thus, both the adsorption capacity and the catalytic activity are the two factors that equally govern efficient photocatalysis. As shown in Figure $5 \mathrm{a}$, the $\mathrm{MoS}_{2}$ with a 2D layered structure exhibited an almost two times higher $\mathrm{RhB}$ adsorption capacity than that of the $\mathrm{Bi}_{2} \mathrm{~S}_{3}$ analog under identical conditions, indicating that anchoring $\mathrm{MoS}_{2}$ onto $\mathrm{Bi}_{2} \mathrm{~S}_{3}$ could significantly enhance its adsorption capacity for subsequent catalytic reactions. However, because of the severe aggregation and the low specific surface area of the self-assembled $\mathrm{MoS}_{2}$ flower-like microspheres (Supplementary Figures S1b-f), ${ }^{25,35}$ its $\mathrm{RhB}$ adsorption capacity $\left(37 \mathrm{mg} \mathrm{g}^{-1}\right)$ was substantially smaller than that of $3 \mathrm{D}$ $\mathrm{MoS}_{2} / \mathrm{Bi}_{2} \mathrm{~S}_{3}$ (50 mg g ${ }^{-1}$; Supplementary Figures S12a-c), although less $\mathrm{MoS}_{2}$ mass was present in the hybrid. Furthermore, RhB might be adsorbed by van der Waals or $\pi-\pi$ interactions and hydrogen bonding rather than electrostatic forces, ${ }^{41}$ despite the negatively charged surface of the photocatalysts at the given $\mathrm{pH}$ of 3.95-5.68 (Supplementary Figures S13a and $b$ ).

For the $3 \mathrm{D} \mathrm{MoS}_{2} / \mathrm{Bi}_{2} \mathrm{~S}_{3}$, the MoBi-30 exhibited the largest adsorption capacity for low-concentration $\mathrm{RhB}$ and thus the highest removal efficiency for both the adsorption and degradation processes (Figure 5a). The 3D MoBi-30 had the highest specific surface area of $25.65 \mathrm{~m}^{2} \mathrm{~g}^{-1}$ (Supplementary Figure S6), which might be due to the dense, outstretched and ultrathin well-defined plate-like morphology of the $\mathrm{MoS}_{2}$ nanosheets and the sufficient inter-space of the $\mathrm{Bi}_{2} \mathrm{~S}_{3}$ micro-flowers self-assembled by $1 \mathrm{D}$ micro-rods (Figure 1). For comparison, the physically mixed $\mathrm{Bi}_{2} \mathrm{~S}_{3}$ micro-flowers and $\mathrm{MoS}_{2}$ nanosheets (BiMo Mixed in Figure 5a) showed a much lower adsorption efficiency because of their loose and aggregated structure of $\mathrm{MoS}_{2}$ and $\mathrm{Bi}_{2} \mathrm{~S}_{3}$. This is further proven by the control experiments with $\mathrm{MoS}_{2}$ nanosheets with either inadequate or excessive layers.

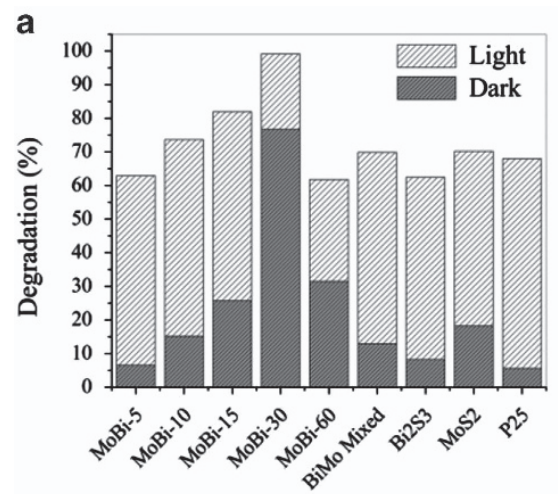

C

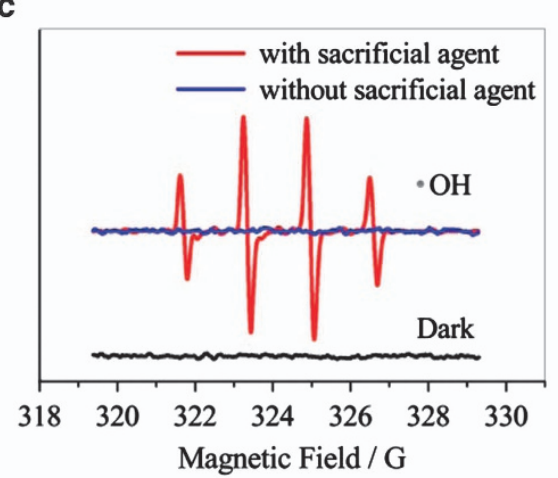

b

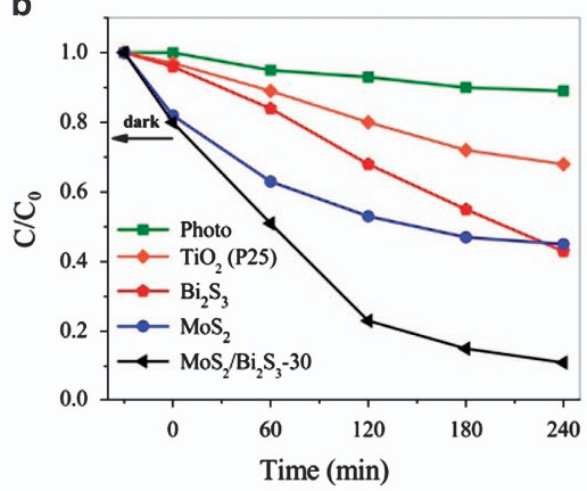

d

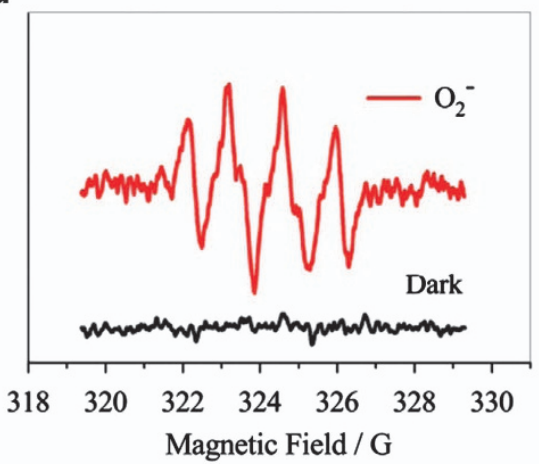

Figure 5 Photocatalytic degradation of rhodamine $\mathrm{B}(\mathrm{RhB})$ and atrazine by different photocatalysts (a, b); ESR signals of the 5,5-dimethyl-pyrroline-N-oxide (DMPO)-trapped $\bullet \mathrm{OH}$ and DMPO-trapped $\bullet \mathrm{O}_{2}{ }^{-}$on the $3 \mathrm{D} \mathrm{MoS}_{2} / \mathrm{Bi}_{2} \mathrm{~S}_{3}(\mathrm{MoBi}-30)$ under visible light and in the dark in the presence or absence of $\mathrm{S}^{2-} / \mathrm{SO}_{3}{ }^{2-}$ as a sacrificial agent (c, d). 
a
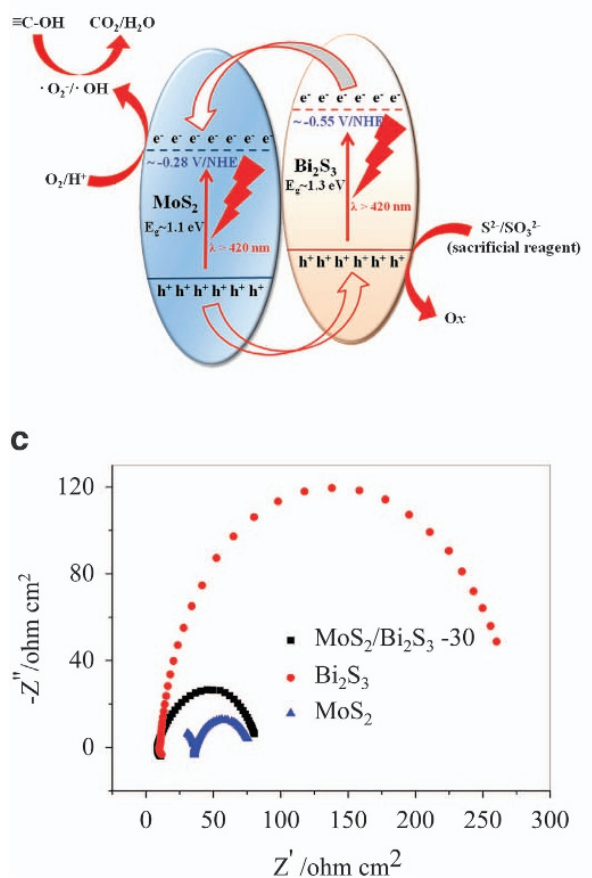

b

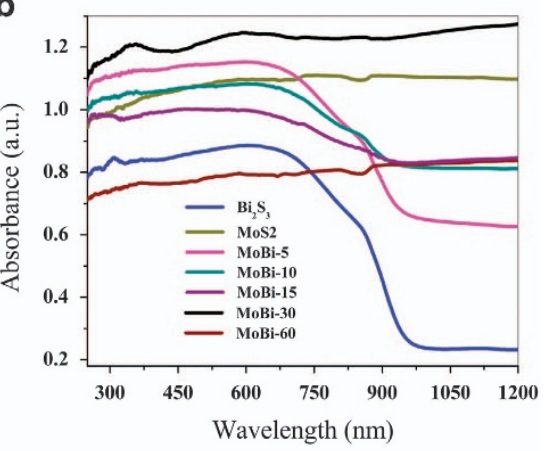

d

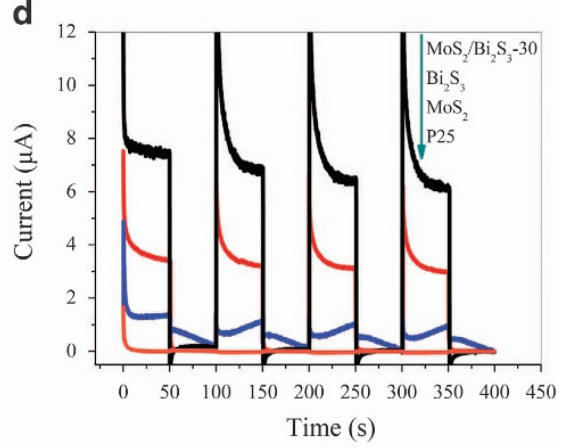

Figure 6 Photocatalytic mechanism of $3 \mathrm{D} \mathrm{MoS}_{2} / \mathrm{Bi}_{2} \mathrm{~S}_{3}$ under visible light irradiation (a); diffuse reflectance spectra (DRS) of $\mathrm{MoS}_{2}, \mathrm{Bi}_{2} \mathrm{~S}_{3}$ and $3 \mathrm{D}$ $\mathrm{MoS}_{2} / \mathrm{Bi}_{2} \mathrm{~S}_{3}$ with different layers of $\mathrm{MoS}_{2}$ nanosheets (b); electrochemical impedance spectroscopy (EIS) of $\mathrm{MoS}_{2}, \mathrm{Bi}_{2} \mathrm{~S}_{3}$ and $3 \mathrm{D} \mathrm{MoS} / \mathrm{Bi}_{2} \mathrm{~S}_{3}$ ( $\mathrm{MoBi}-30$ ) at an open-circuit potential of $-0.33 \mathrm{~V}$ (versus $\mathrm{Ag} / \mathrm{AgCl}$ ) (c); photocurrent of $\mathrm{MoS}_{2}, \mathrm{Bi}_{2} \mathrm{~S}_{3}, 3 \mathrm{D} \mathrm{MoS}_{2} / \mathrm{Bi}_{2} \mathrm{~S}_{3}(\mathrm{MoBi}-30$ ) and $\mathrm{P} 25$ under visible light irradiation at an external bias of $+0.25 \mathrm{~V}$ (versus $\mathrm{Ag} / \mathrm{AgCl})(\mathrm{d})$.

The samples with few $\mathrm{MoS}_{2}$ layers (MoBi-5, -10 and -15) showed a reduced ability to adsorb $\mathrm{RhB}$ with the decreasing layer of $\mathrm{MoS}_{2}$ nanosheets, whereas the excessive $\mathrm{MoS}_{2}$ nanosheets substantially damaged the $3 \mathrm{D}$ structure of the $\mathrm{Bi}_{2} \mathrm{~S}_{3}$ micro-flowers, MoBi-60, by filling the inter-spaces between micro-rods. In addition, the overall RhB removal efficiency of BiMo-30 was considerably higher than that of $\mathrm{Bi}_{2} \mathrm{~S}_{3}, \mathrm{MoS}_{2}$ and commercial P25 (Figure 5a), which should mainly be attributed to the excellent adsorption capacity of the $3 \mathrm{D}$ $\mathrm{MoS}_{2} / \mathrm{Bi}_{2} \mathrm{~S}_{3}$.

Moreover, the excellent catalytic activity of the 3D $\mathrm{MoS}_{2} / \mathrm{Bi}_{2} \mathrm{~S}_{3}$ could be further proven by the adsorption-promoted photocatalytic degradation of atrazine, a typical herbicide widely present in water. After 240 min of irradiation, the highest removal efficiency of $89 \%$ was obtained by the $3 \mathrm{D} \mathrm{MoS} 2 / \mathrm{Bi}_{2} \mathrm{~S}_{3}$ (MoBi-30; Figure $5 \mathrm{~b}$ ), that is, higher than the results of some typical visible photocatalysts (Supplementary Figure S14). ${ }^{42-44}$ The $3 \mathrm{D} \mathrm{MoS}_{2} / \mathrm{Bi}_{2} \mathrm{~S}_{3}$ (MoBi-30) exhibited not only the largest adsorption capacity, but also the highest catalytic activity for atrazine degradation under visible light irradiation. Apparently, its high catalytic activity should be attributed to the strong synergistic effects between the good interfacial mass transfer and the rapid surface chemical reaction. In addition, atrazine might be dominantly adsorbed in its molecular form onto the negatively charged photocatalyst surfaces at the given $\mathrm{pH}$ (Supplementary Figure S13c). ${ }^{45}$ Furthermore, its photocatalytic activity remained high after five cycles (Supplementary Figure S15), suggesting its good photocatalytic stability. The observed partial activity loss might be due to incomplete photocatalyst collection, organic surface deactivation and decreased adsorption capacity. ${ }^{46}$

The active species from $3 \mathrm{D} \mathrm{MoS}_{2} / \mathrm{Bi}_{2} \mathrm{~S}_{3}$ in the photocatalytic degradation of atrazine were investigated by conducting ESR and radical inhibition tests. As shown in Figure 5c, the ESR spectra generated from 5,5-dimethyl-pyrroline- $\mathrm{N}$-oxide--OH adduct with a characteristic 1:2:2:1 pattern was measured in the $3 \mathrm{D} \mathrm{MoS}_{2} / \mathrm{Bi}_{2} \mathrm{~S}_{3}$ aqueous solution with $\mathrm{S}^{2-} / \mathrm{SO}_{3}{ }^{2-}$ as a sacrificial agent. In comparison, no ESR spectra were observed in the absence of $\mathrm{S}^{2-} / \mathrm{SO}_{3}{ }^{2-}$. This result should mainly be attributed to the rapid recombination of photo-excited electron-hole pairs with weak redox potentials. For $\cdot \mathrm{O}_{2}{ }^{-}$, the ESR spectra generated from the 5,5-dimethyl-pyrroline-Noxide-- $\mathrm{O}_{2}{ }^{-}$adduct with a characteristic $1: 1: 1: 1$ pattern were measured only in the $3 \mathrm{D} \mathrm{MoS}_{2} / \mathrm{Bi}_{2} \mathrm{~S}_{3}$ methanol solution in the presence of $\mathrm{S}^{2-} / \mathrm{SO}_{3}{ }^{2-}$ (Figure $5 \mathrm{~d}$ ). These results indicate that both $\cdot \mathrm{OH}$ and $\cdot \mathrm{O}_{2}{ }^{-}$ have important roles in the photocatalytic degradation of atrazine on the $3 \mathrm{D} \mathrm{MoS}_{2} / \mathrm{Bi}_{2} \mathrm{~S}_{3}$ under visible light irradiation. In addition, the active species were further explored in the radical inhibition tests, in which $\mathrm{S}^{2-} / \mathrm{SO}_{3}{ }^{2-}$, benzoquinone and tert-butyl alcohol were used as scavengers for photo-generated holes, $\cdot \mathrm{O}_{2}{ }^{-}$and $\cdot \mathrm{OH}$, respectively. Subtracting the contribution of dark adsorption, the net efficiency of removing atrazine by photocatalytic degradation was substantially improved from 15 to $70 \%$ (total organic carbon removal of $38.7 \%$ ) when the photo-generated holes were captured (Supplementary Figure S16). However, the inhibition of either $\cdot \mathrm{OH}$ or $\cdot \mathrm{O}_{2}^{-}$considerably decreased the net atrazine removal efficiency from $70 \%$ to $<10 \%$. These results are consistent with the ESR studies (Figures $5 \mathrm{c}$ and $\mathrm{d}$ ) and further indicate that both $\cdot \mathrm{OH}$ and $\cdot \mathrm{O}_{2}{ }^{-}$were the main active species for atrazine degradation by the $3 \mathrm{D} \mathrm{MoS} / \mathrm{Bi}_{2} \mathrm{~S}_{3}$.

Photocatalytic mechanism of $3 \mathrm{D} \mathrm{MoS}_{2} / \mathrm{Bi}_{2} \mathrm{~S}_{3}$

The photocatalytic mechanism of the 3D $\mathrm{MoS}_{2} / \mathrm{Bi}_{2} \mathrm{~S}_{3}$ hybrid under visible light irradiation is tentatively proposed (Figure $6 \mathrm{a}$ ). To elucidate this mechanism, the energy structures of both $\mathrm{Bi}_{2} \mathrm{~S}_{3}$ and $\mathrm{MoS}_{2}$ were first studied to explore the separation, transfer and utilization properties of electron-hole pairs in the $3 \mathrm{D} \mathrm{MoS}_{2} / \mathrm{Bi}_{2} \mathrm{~S}_{3}$. For $\mathrm{Bi}_{2} \mathrm{~S}_{3}$, the band 
gap energy was determined to be $\sim 1.30 \mathrm{eV}$ from its diffuse reflectance spectra spectrum by the Tauc equation (Supplementary Figures S17a and $6 \mathrm{~b}$ ), and its conduction band potential was measured to be $\sim-0.55 \mathrm{~V} / \mathrm{NHE}$ (Supplementary Figure S17c). Similarly, $\mathrm{MoS}_{2}$ is a narrow band gap semiconductor with a gap energy determined to be $\sim 1.10 \mathrm{eV}$ (Supplementary Figure S17b), and its conduction band potential was measured to be $\sim-0.28 \mathrm{~V} / \mathrm{NHE}$ (Supplementary Figure S17d). The measured conduction band potential of $\mathrm{Bi}_{2} \mathrm{~S}_{3}$ was sufficiently more negative than that of $\mathrm{MoS}_{2}$, and thus, a typical typeII band gap alignment could be constructed between $\mathrm{Bi}_{2} \mathrm{~S}_{3}$ and $\mathrm{MoS}_{2}$ within the $3 \mathrm{D} \mathrm{MoS}_{2} / \mathrm{Bi}_{2} \mathrm{~S}_{3}$ (Figure 6a), according to the Anderson model. With this mechanism, the photo-generated electrons in $\mathrm{Bi}_{2} \mathrm{~S}_{3}$ under visible light irradiation were anticipated to be transferred to $\mathrm{MoS}_{2}$, and a very enhanced separation, transfer and utilization efficiency of photocarriers was expected (reactions 1 and 2). The collected holes were consumed by $\mathrm{S}^{2-} / \mathrm{SO}_{3}{ }^{2-}$, whereas the collected electrons reacted with the absorbed oxygen molecules on the $\mathrm{MoS}_{2}$ surface to generate $\cdot \mathrm{O}_{2}^{-}$(reaction 3 ), which could further react with the surface-adsorbed protons to quickly produce $\cdot \mathrm{OH}$ to degrade the pollutants (Figure 6a; reactions 4 and 5). The enhanced oxygen reduction capacity of $\mathrm{MoS}_{2}$ and the better hydrophilic property of $3 \mathrm{D} \mathrm{MoS}_{2} / \mathrm{Bi}_{2} \mathrm{~S}_{3}$ favored the generation of both $\cdot \mathrm{O}_{2}^{-}$and $\cdot \mathrm{OH}$ (Supplementary Figures S18 and S19). ${ }^{47}$

$$
\begin{aligned}
& \mathrm{MoS}_{2} / \mathrm{Bi}_{2} \mathrm{~S}_{3}+h v \rightarrow \mathrm{MoS}_{2}\left(\mathrm{e}^{-}+\mathrm{h}^{+}\right) / \mathrm{Bi}_{2} \mathrm{~S}_{3}\left(\mathrm{e}^{-}+\mathrm{h}^{+}\right) \\
& \mathrm{MoS}_{2}\left(\mathrm{e}^{-}+\mathrm{h}^{+}\right) / \mathrm{Bi}_{2} \mathrm{~S}_{3}\left(\mathrm{e}^{-}+\mathrm{h}^{+}\right) \rightarrow \mathrm{MoS}_{2}\left(\mathrm{e}^{-}\right) / \mathrm{Bi}_{2} \mathrm{~S}_{3}\left(\mathrm{~h}^{+}\right) \\
& \mathrm{MoS}_{2}\left(\mathrm{e}^{-}\right) / \mathrm{Bi}_{2} \mathrm{~S}_{3}\left(\mathrm{~h}^{+}\right)+\mathrm{O}_{2} \rightarrow \cdot \mathrm{O}_{2}{ }^{-} \\
& \mathrm{MoS}_{2}\left(\mathrm{e}^{-}\right) / \mathrm{Bi}_{2} \mathrm{~S}_{3}\left(\mathrm{~h}^{+}\right)+\mathrm{O}_{2}+2 \mathrm{H}^{+} \rightarrow \mathrm{H}_{2} \mathrm{O}_{2} \\
& \cdot \mathrm{O}_{2}^{-}+\mathrm{H}_{2} \mathrm{O}_{2} \rightarrow \mathrm{OH}+\cdot \mathrm{OH}^{-}+\mathrm{O}_{2}
\end{aligned}
$$

To explore the observed high catalytic activity of $3 \mathrm{D} \mathrm{MoS}_{2} / \mathrm{Bi}_{2} \mathrm{~S}_{3}$, its optical properties were evaluated. The diffuse reflectance spectra of the $3 \mathrm{D} \mathrm{MoS}_{2} / \mathrm{Bi}_{2} \mathrm{~S}_{3}$ showed a wide absorption band covering a broader visible light region (Figure 6b) owing to the intrinsic bandgaps of both $\mathrm{Bi}_{2} \mathrm{~S}_{3}$ and $\mathrm{MoS}_{2}$. After the $\mathrm{MoS}_{2}$ nanosheets grew locally on the $\mathrm{Bi}_{2} \mathrm{~S}_{3}$ micro-flowers, the absorption edge was substantially extended to a longer wavelength, and an enhanced absorption intensity in the visible light region was clearly observed (Figure 6b). Thus, $3 \mathrm{D} \mathrm{MoS}_{2} / \mathrm{Bi}_{2} \mathrm{~S}_{3}$ could be excited to generate many more electron-hole pairs under visible light irradiation, possibly leading to an enhanced photocatalytic activity for pollutant degradation. In addition, the favorable electronic coupling for the rapid electron transport from the less conductive $\mathrm{Bi}_{2} \mathrm{~S}_{3}$ micro-flowers to the more conductive $\mathrm{MoS}_{2}$ nanosheets in $3 \mathrm{D}$ $\mathrm{MoS}_{2} / \mathrm{Bi}_{2} \mathrm{~S}_{3}$ (Figure 6c) confirmed that the short-circuit photocurrent measured on 3D MoS $2 / \mathrm{Bi}_{2} \mathrm{~S}_{3}$ had a higher intensity and a better stability than that measured on the $\mathrm{Bi}_{2} \mathrm{~S}_{3}, \mathrm{MoS}_{2}$ and P25 references (Figure 6d). The applied external bias, $+0.447 \mathrm{~V} / \mathrm{NHE}$, was too low to generate any significant faradic anodic current from water oxidation by the oxygen evolution reaction (as confirmed by the rather low dark current in Figure 6d), and $\mathrm{E}^{0} \mathrm{H}_{2} \mathrm{O} / \mathrm{O} 2=+1.23 \mathrm{~V} / \mathrm{NHE}$. Thus, the measured photocurrents on the $3 \mathrm{D} \mathrm{MoS} / \mathrm{Bi}_{2} \mathrm{~S}_{3}$ hybrid and its $\mathrm{Bi}_{2} \mathrm{~S}_{3}$, $\mathrm{MoS}_{2}$ and P25 references were mostly ascribed to the efficient generation, separation and transfer of the photo-generated electronhole pairs under visible light irradiation $(\lambda>420 \mathrm{~nm})$, as described by the model of hole injection into the aqueous electrolyte and electron injection into the underlying substrate and ultimately to the counter electrode. Thus, the higher and more stable photocurrent measured on $3 \mathrm{D} \mathrm{MoS}_{2} / \mathrm{Bi}_{2} \mathrm{~S}_{3}$ indicates its higher generation, separation and transfer efficiency of reactive photocarriers under visible light irradiation. In principle, the superior photochemical, electrochemical and photoelectrochemical properties of the $3 \mathrm{D} \mathrm{MoS}_{2} / \mathrm{Bi}_{2} \mathrm{~S}_{3}$ could favor the largest amount of photo-generated $\cdot \mathrm{OH}$ (Supplementary Figures S20a-d) and the highest photocatalytic activity for the degradation of refractory pollutants, such as $\mathrm{RhB}$ and atrazine (Figures $5 \mathrm{a}$ and $\mathrm{b}$ ).

\section{CONCLUSIONS}

In summary, we developed a facile and general hydrothermal method to prepare a novel 3D flower-like $\mathrm{MoS}_{2} / \mathrm{Bi}_{2} \mathrm{~S}_{3}$ heterostructure and to simultaneously tune the layers of $\mathrm{MoS}_{2}$ cocatalysts. With this method, $\mathrm{Bi}_{2} \mathrm{~S}_{3}$ was first generated, which then acted as the sacrificial template for localized $\mathrm{MoS}_{2}$ formation via a cation-exchange mechanism. The 3D $\mathrm{MoS}_{2} / \mathrm{Bi}_{2} \mathrm{~S}_{3}$ exhibited a strong adsorption capacity and excellent photocatalytic activity toward the degradation of both $\mathrm{RhB}$ and atrazine. These findings are important for the development of novel S-based photocatalyst hybrids, for example, $\mathrm{Sb}_{2} \mathrm{~S}_{3} / \mathrm{MoS}_{2}$, for various environmental and energy applications.

\section{CONFLICT OF INTEREST}

The authors declare no conflict of interest.

\section{ACKNOWLEDGEMENTS}

We thank the National Science Foundation of China (51208488, 21261160489 and 51538011) and the Program for Changjiang Scholars and Innovative Research Team in University of the Ministry of Education of China for the support of this work.

Author contributions: A.-Y.Z. and H.-Q.Y. conceived the idea. L.-L.L., A.-Y.Z., Q.R., X.Z. and Y.-X.H. planned and performed the experiments and collected and analyzed the data. J.-J.C. performed the DFT calculations. L.-L.L., A.-Y.Z. and H.-Q.Y. co-wrote the manuscript. All authors discussed the results and commented on the manuscript.

1 Kershaw, S. V., Susha, A. S. \& Rogach, A. L. Narrow bandgap colloidal metal chalcogenide quantum dots: synthetic methods, heterostructures, assemblies, electronic and infrared optical properties. Chem. Soc. Rev. 42, 3033-3087 (2013).

2 Rhee, J. H., Chung, C. C. \& Diau, W. G. A perspective of mesoscopic solar cells based on metal chalcogenide quantum dots and organometal-halide perovskites. NPG Asia Mater. 5, e68 (2013).

3 Kong, D., Cha, J. J., Wang, H., Lee, H. R. \& Cui, Y. First-row transition metal dichalcogenide catalysts for hydrogen evolution reaction. Energy Environ. Sci. 6, 3553-3558 (2013)

4 Gao, X., Wu, H. B., Zhang, L., Zhong, Y., Hu, Y. \& Lou, X. W. Formation of mesoporous heterostructured $\mathrm{BiVO}_{4} / \mathrm{Bi}_{2} \mathrm{~S}_{3}$ hollow discoids with enhanced photoactivity. Angew. Chem. Int. Ed. 53, 5917-5921 (2014).

5 Li, L., Sun, L. J., Huang, Y. Y., Qin, Y., Zhao, N. N., Gao, J. N., Li, M. X., Zhou, H. H. \& Qi, L. M. Topotactic transformation of single-crystalline precursor discs into disc-like $\mathrm{Bi}_{2} \mathrm{~S}_{3}$ nanorod networks. Adv. Funct. Mater. 18, 1194-1201 (2008).

6 Liu, Y., Yu, Y. X. \& Zhang, W. D. $\mathrm{MoS}_{2} / \mathrm{CdS}$ heterojunction with high photoelectrochemical activity for $\mathrm{H}_{2}$ evolution under visible light: the role of $\mathrm{MoS}_{2}$. J. Phys. Chem. C 117, 12949-12957 (2013).

7 Liu, Z. Q., Huang, W. Y., Zhang, Y. M. \& Tong, Y. X. Facile hydrothermal synthesis of $\mathrm{Bi}_{2} \mathrm{~S}_{3}$ spheres and $\mathrm{CuS} / \mathrm{Bi}_{2} \mathrm{~S}_{3}$ composites nanostructures with enhanced visible-light photocatalytic performances. CrystEngComm. 14, 8261-8267 (2012).

8 Narayanan, R., Deepa, M., Friebel, F. \& Srivastava, A. K. A CdS/Bi ${ }_{2} \mathrm{~S}_{3}$ bilayer and a poly (3,4-ethylenedioxythiophene)/S $S_{2}$ interface control quantum dot solar cell performance. Electrochim. Acta 105, 599-611 (2013).

9 Fang, Z Liu, Y. F. Fan, Y. T., Ni, Y. H. Wei, X. W. Tang, K. B., Shen, J. M. \& Chen, Y. Epitaxial growth of $\mathrm{CdS}$ nanoparticle on $\mathrm{Bi}_{2} \mathrm{~S}_{3}$ nanowire and photocatalytic application of the heterostructure. J. Phys. Chem. C 115, 13968-13976 (2011).

$10 \mathrm{Wu}$, Z., Chen, L., Xing, C., Jiang, D., Xie, J. \& Chen, M. Controlled synthesis of $\mathrm{Bi}_{2} \mathrm{~S}_{3} / \mathrm{ZnS}$ microspheres by an in situ ion-exchange process with enhanced visible light photocatalytic activity. Dalton Trans. 42, 12980-12988 (2013).

$11 \mathrm{He}, \mathrm{H}$., Berglund, Sean, P., Xiao, P. \& Chemelewski, W. D. Nanostructured $\mathrm{Bi}_{2} \mathrm{~S}_{3} / \mathrm{WO}_{3}$ heterojunction films exhibiting enhanced photoelectrochemical performance. J. Mater. Chem. A 1, 12826-12834 (2013).

12 Tan, C. \& Zhang, H. Two-dimensional transition metal dichalcogenide nanosheet-based composites. Chem. Soc. Rev. 44, 2713-2731 (2015). 
13 Huang, X., Zeng, Z. \& Zhang, H. Metal dichalcogenide nanosheets: preparation, properties and applications. Chem. Soc. Rev. 42, 1934-1946 (2013).

14 Zhang, X. \& Xie, Y. Recent advances in free-standing two-dimensional crystals with atomic thickness: design, assembly and transfer strategies. Chem. Soc. Rev. 42, 8187-8199 (2013).

15 Karunadasa, H. I., Montalvo, E., Sun, Y. J., Majda, M., Long, J. R. \& Chang, C. J. A molecular $\mathrm{MoS}_{2}$ edge site mimic for catalytic hydrogen generation. Science 335, 698-702 (2012).

16 Chang, K., Mei, Z. W., Wang, T., Kang, Q., Yang, S. X. \& Ye, J. H. MoS 2 /Graphene cocatalyst for efficient photocatalytic $\mathrm{H}_{2}$ evolution under visible light irradiation. ACS Nano 8, 7078-7087 (2014).

17 Wan, Z., Yin, Z., Du, Y., Huang, X., Zeng, Z., Fan, Z., Liu, H., Wang, J. \& Zhang, H. Core-shell structure of hierarchical quasi-hollow $\mathrm{MoS}_{2}$ microspheres encapsulated porous carbon as stable anode for Li-ion batteries. Small 10, 4975-4981 (2014).

18 Kibsgaard, J., Chen, Z., Reinecked, B. \& Jaramillo, T. F. Engineering the surface structure of $\mathrm{MoS}_{2}$ to preferentially expose active edge sites for electrocatalysis. Nat. Mater. 11, 963-969 (2012).

19 Weng, B., Zhang, X., Zhang, N., Tang, Z. R. \& Xu, Y. J. Two-dimensional MoS nanosheet-coated $\mathrm{Bi}_{2} \mathrm{~S}_{3}$ discoids: synthesis, formation mechanism, and photocatalytic application. Langmuir 31, 4314-4322 (2015).

20 Wang, S., Li, X., Chen, Y., Cai, X., Yao, H., Gao, W., Zheng, Y., An, X., Shi, J. \& Chen, H. A facile one-pot synthesis of a two-dimensional $\mathrm{MoS}_{2} / \mathrm{Bi}_{2} \mathrm{~S}_{3}$ composite theranostic nanosystem for multi-modality tumor imaging and therapy. Adv. Mater. 17, 2775-2782 (2015)

21 Xiang, Q., Yu, J. G. \& Jaroniec, M. Synergetic effect of $\mathrm{MoS}_{2}$ and graphene as cocatalysts for enhanced photocatalytic $\mathrm{H}_{2}$ production activity of $\mathrm{TiO}_{2}$ nanoparticles. J. Am. Chem. Soc. 134, 6575-6578 (2012).

22 Liu, M., Li, F., Sun, Z., Ma, L., Xu, L. \& Wang, Y. Noble-metal-free photocatalysts $\mathrm{MoS}_{2}$-graphene/CdS mixed nanoparticles/nanorods morphology with high visible light efficiency for $\mathrm{H}_{2}$ evolution. Chem. Commun. 50, 11004-11007 (2014).

$23 \mathrm{Jia}$, T. T., Kolpin, A., Ma, C. S., Chan, R. C.-T., Kwok, W.-M. \& Tsang, S. C. E. A graphene dispersed $\mathrm{CdS}-\mathrm{MoS}_{2}$ nanocrystal ensemble for cooperative photocatalytic hydrogen production from water. Chem. Commun. 50, 1185-1188 (2014).

24 Lang, D., Shen, T. \& Xiang, Q. Roles of $\mathrm{MoS}_{2}$ and graphene as cocatalysts in the enhanced visible-light photocatalytic $\mathrm{H}_{2}$ production activity of multiarmed $\mathrm{CdS}$ nanorods. ChemCatChem. 7, 943-951 (2015).

25 Li, Y. G., Wang, H. L., Xie, L. M., Liang, Y. Y., Hong, G. S. \& Dai, H. J. MoS nanoparticles grown on graphene: an advanced catalyst for the hydrogen evolution reaction. J. Am. Chem. Soc. 133, 7296-7299 (2011).

26 Zong, X., Yan, H. J., Wu, G. P., Ma, G. J., Wen, F. Y., Wang, L. \& Li, C. Enhancement of photocatalytic $\mathrm{H}_{2}$ evolution on CdS by loading $\mathrm{MoS}_{2}$ as cocatalyst under visible light irradiation. J. Am. Chem. Soc. 130, 7176-7177 (2008).

27 Ding, S., Zhang, D., Chen, J. S. \& Lou, X. W. Facile synthesis of hierarchical MoS microspheres composed of few-layered nanosheets and their lithium storage properties. Nanoscale 4, 95-98 (2012).

28 Zhou, W., Yin, Z., Du, Y., Huang, X., Zeng, Z., Fan, Z., Liu, H., Wang, J. \& Zhang, H. Synthesis of few-layer $\mathrm{MoS}_{2}$ nanosheet-coated $\mathrm{TiO}_{2}$ nanobelt heterostructures for enhanced photocatalytic activities. Small 9, 140-147 (2013).

29 Seo, B., Jung, G. Y., Sa, Y. J., Jeong, H. Y., Cheon, J. Y., Lee, J. H., Kim, H. Y., Kim, J. C., Shin, H. S., Kwak, S. K. \& Joo, S. H. Monolayer-precision synthesis of molybdenum sulfide nanoparticles and their nanoscale size effects in the hydrogen evolution reaction. ACS Nano 9, 3728-3739 (2015).

30 Chen, J., Wu, X. J., Yin, L., Li, B., Hong, X., Fan, Z., Chen, B., Xue, C. \& Zhang, H. One-pot synthesis of CdS nanocrystals hybridized with single-layer transition-metal dichalcogenide nanosheets for efficient photocatalytic hydrogen evolution. Angew. Chem. Int. Ed. 54, 1210-1214 (2015).

31 Wang, J., Liu, J., Chao, D., Yan, J., Lin, J. \& Shen, Z. X. Self-assembly of honeycomblike $\mathrm{MoS}_{2}$ nanoarchitectures anchored into graphene foam for enhanced lithium-ion storage. Adv. Mater. 26, 7162-7169 (2014).
32 Wang, P. P., Sun, H., Ji, Y., Li, W. \& Wang, X. Three-dimensional assembly of single-layered $\mathrm{MoS}_{2}$. Adv. Mater. 26, 964-969 (2014).

33 Zhou, F., Xin, S., Liang, H. W., Song, L. T. \& Yu, S. H. Carbon nanofibers decorated with molybdenum disulfide nanosheets: synergistic lithium storage and enhanced electrochemical performance. Angew. Chem. Int. Ed. 53, 11552-11556 (2014).

34 Yang, L., Wang, S., Mao, J., Deng, J., Gao, Q., Tang, Y. \& Schmidt, O. G. Hierarchical $\mathrm{MoS}_{2} /$ polyaniline nanowires with excellent electrochemical performance for lithium-ion batteries. Adv. Mater. 25, 1180-1184 (2013).

35 Chou, S. S., De, M., Kim, J., Byun, S., Dykstra, C., Yu, J., Huang, J. \& Dravid, V. P. Ligand conjugation of chemically exfoliated $\mathrm{MoS}_{2}$. J. Am. Chem. Soc. 135, 4584-4587 (2013).

36 Knoxville, T. N. \& John, A. D. Lange's Handbook of Chemistry. 15th edition, 8.24-8.72 (McGraw-Hill, New York City, NY, USA, 1999).

37 Lisicki, N. M. \& Böltz, D. F. UV spectrophotometric determination of bismuth by iodide and thiourea. Anal. Chem. 27, 1722-1724 (1955).

38 Ivanova, E., Yan, X. P. \& Adams, F. Determination of bismuth in cod muscle, lake and river sediment by flow injection on-line sorption preconcentration in a knotted reactor coupled with electrothermal atomic absorption spectrometry. Anal. Chim. Acta 354, 7-13 (1997).

39 Tang, Z., Wang, Y., Shanbhag, S. \& Kotov, N. A. Spontaneous CdTe $\rightarrow$ alloy $\rightarrow$ CdS transition of stabilizer-depleted CdTe nanoparticles induced by EDTA. J. Am. Chem. Soc. 128, 7036-7042 (2006).

40 Liu, Y. H., Wang, F., Hoy, J., Wayman, V. L., Steinberg, L. K., Loomis, R. A. \& Buhro, W. E. Bright core-shell semiconductor quantum wires. J. Am. Chem. Soc. 134, 18797-18803 (2012).

41 Gao, Y. W., Wang, Y. \& Zhang, H. Removal of Rhodamine B with Fe-supported bentonite as heterogeneous photo-Fenton catalyst under visible irradiation. Appl. Catal. $B$ 178, 29-36 (2015).

$42 \mathrm{Xu}, \mathrm{X}$, Hu, L. F., Gao, N., Liu, S. X., Wageh, S., Alghamdi, A., Alshahrie, A. \& Fang, X. S. Controlled growth from ZnS nanoparticles to ZnS-CdS nanoparticle hybrids with enhanced photoactivity. Adv. Funct. Mater. 25, 445-454 (2015).

43 Zhang, X., Wang, X. B., Wang, L. W., Wang, W. K., Long, L. L., Li, W. W. \& Yu, H. Q. Synthesis of a highly efficient $\mathrm{BiOCl}$ single-crystal nanodisk photocatalyst with exposing \{001\} facets. ACS Appl. Mater. Interfaces 6, 7766-7772 (2014).

44 Pan, C., Xu, J., Wang, Y., Li, D. \& Zhu, Y. Dramatic activity of $\mathrm{C}_{3} \mathrm{~N}_{4} / \mathrm{BiPO}_{4}$ photocatalyst with core/shell structure formed by self-assembly. Adv. Funct. Mater. 22 1518-1524 (2012)

45 Gai, K., Shi, B. Y., Yan, X. M. \& Wang, D. S. Effect of dispersion on adsorption of atrazine by aqueous suspensions of fullerenes. Environ. Sci. Technol. 45, 5959-5965 (2011).

46 Long, L. L., Zhang, A. Y., Huang, Y. X., Zhang, X. \& Yu, H. Q. A robust cocatalyst $P_{4} S$ uniformly anchored onto $\mathrm{Bi}_{2} \mathrm{~S}_{3}$ nanorods for enhanced visible light photocatalysis. J. Mater. Chem. A 3, 4301-4306 (2015).

47 Chen, S., Shen, S., Liu, G., Qi, Y., Zhang, F. \& Li, C. Interface engineering of a $\mathrm{CoO}_{X} / \mathrm{Ta}_{3} \mathrm{~N}_{5}$ photocatalyst for unprecedented water oxidation performance under visible-light-irradiation. Angew. Chem. Int. Ed. 54, 3047-3051 (2015).

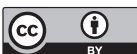

This work is licensed under a Creative Commons Attribution 4.0 International License. The images or other third party material in this article are included in the article's Creative Commons license, unless indicated otherwise in the credit line; if the material is not included under the Creative Commons license, users will need to obtain permission from the license holder to reproduce the material. To view a copy of this license, visit http:// creativecommons.org/licenses/by/4.0/

Supplementary Information accompanies the paper on the NPG Asia Materials website (http://www.nature.com/am) 